American J. of Engineering and Applied Sciences 1 (1): 66-75, 2008

ISSN 1941-7020

(C) 2008 Science Publications

\title{
Decentralized Controller Design for Static Synchronous Compensator Using Robust Quantitative Feedback Theory Method
}

\author{
Seyed Abbas Taher, Reza Hematti, Ali Abdolalipour and Majid Nemati \\ Department of Electrical Engineering, University of Kashan, Kashan, Iran
}

\begin{abstract}
The Static Synchronous Compensator (STATCOM) provides shunt compensation in similar way to the Static VAR Compensator (SVC) but utilizes a voltage source converter rather than capacitors and reactor. In practice systems use simple Proportional-Integral (PI) controllers for control of STATCOM. However, since the PI control parameters were usually tuned based on classical or trial-and-error approaches, they were incapable of obtaining good dynamic performance for a wide range of operation conditions and various loads in power system. For this problem, in this research a robust control approach based on the Quantitative Feedback Theory (QFT) method was proposed for the design of STATCOM controllers (AC-voltage regulator and DC-voltage regulator) and also supplementary damping controller for increase of power system oscillations damping is developed. A Single-Machine Infinite-Bus (SMIB) power system installed with a STATCOM with system parametric uncertainties were considered for case study. The system parametric uncertainties were obtained by changing parameters and load by $45 \%$ simultaneously from their typical values. To show effectiveness of QFT method, the proposed method is compared with a conventional method (classical P-I controller optimized by Genetic Algorithm (GA)). Several linear and non-linear time-domain simulation tests visibly show the validity of proposed method in compare with traditional method.
\end{abstract}

Key words: Flexible AC transmission systems, static synchronous compensator, power system oscillations, quantitative feedback theory, decentralized control

\section{INTRODUCTION}

The Flexible AC Transmission Systems (FACTS) based on power electronics offer an opportunity to enhance controllability, stability and power transfer capability of AC transmission systems ${ }^{[1]}$. The Static Synchronous Compensator (STATCOM) is based on the principle that a voltage-source inverter generates a controllable AC voltage source behind a transformerleakage reactance so that the voltage difference across the reactance produces active and reactive power exchange between the STATCOM and the transmission network. The STATCOM is one of the important FACTS devices and can be used for dynamic compensation of power systems to provide voltage support and stability improvement ${ }^{[2-10]} \cdot \operatorname{In}^{[11]}$ a unified Phillips-Heffron mode ${ }^{[12]}$ of power systems installed with a STATCOM is established. STATCOM has developed from a switch mode voltage-source converter configuration with an energy-storage device (DC capacitor).

However, after modeling of power system with STATCOM, next step is design of proper controllers for this configuration. PID is the most commonly used control algorithm in the process industry. Also, this technique is used to control the FACTS devices ${ }^{[13]}$. However, the nonlinear nature as well as the uncertainties that exist in the system make it difficult to design an effective controller for the FACTS that guarantees fast and stable regulation under all operating conditions. A major source of difficulty is that openloop plant may change. In particular, inaccuracy in plant may cause problems because the plant is part of the feedback loop. To deal with such a problem, instead of using a single model plant, an uncertain model should be considered. This problem has led to the study of applying adaptive controllers for instance ${ }^{[14-15]}$, nonlinear controllers for instance $e^{[16]}$ in the power system stability control. Also, during past decade, the $\mathrm{H}_{\infty}$ optimal robust control design has received increasing attention in power systems. Most of the above methods have been applied in power systems and some of these efforts have contributed to the design of supplementary control for SVC using mixed sensitivity ${ }^{[17]}$, applying $\mu$-synthesis for SVC in order to

Corresponding Author: Seyed Abbas Taher, Department of Electrical Engineering, University of Kashan, km 6 Ravand Road, Kashan, Iran Tel: +98-9131614352 Fax +98-3615559930 
voltage control design ${ }^{[18]}$ and supplementary control design for SVC and STATCOM ${ }^{[19]}$.

The objective of this research is to investigate the STATCOM control problem for a SMIB power system installed with a STATCOM taking into consideration the uncertainties in the parameters of system. A robust decentralized control scheme is designed using QFT method for the design of STATCOM controllers (ACvoltage regulator and DC-voltage regulator). QFT is a robust control method which deals with the effects of uncertainty systematically. It has been successfully applied to the design of the both SISO and MIMO systems. It has also been extended to the nonlinear and time-varying case. Often, results of QFT method is a simple controllers, which is easy in implementation ${ }^{[20-24]}$. To show effectiveness of proposed method, the proposed method is compare to a classical P-I type controller optimized by GA. Simulation results show the QFT controllers guarantee the robust performance for a wide range of operating conditions and have best performance in compare to optimal controllers.

\section{MATERIALS AND METHODS}

Figure 1 shows a Single-Machine Infinite-Bus (SMIB) system equipped with a STATCOM.

The static excitation system, model type IEEEST1A, has been considered. The STATCOM is assumed to be based on Pulse Width Modulation (PWM) converters.

In dynamic of power systems, it is usually important to aim for decentralization of control action to individual areas. The advantages of this operation philosophy are reduction in the controller complexity and suitability for practical implementation. It is shown that each decentralized controller can be designed independently such that performance of the overall

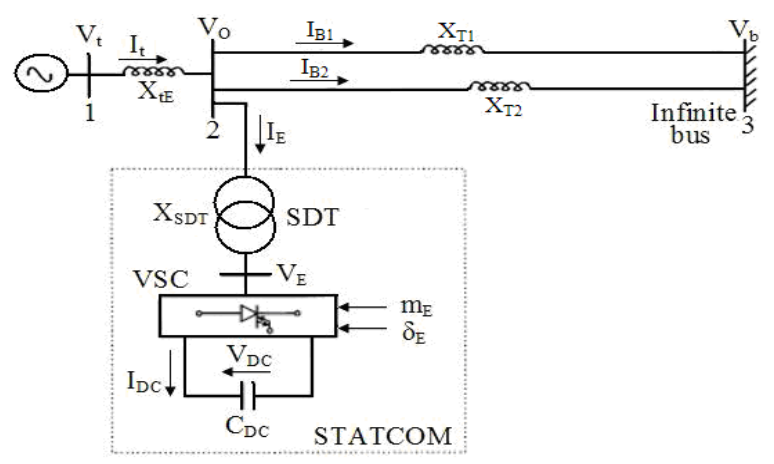

Fig. 1: A SMIB power system installed with STATCOM closed loop systems is guaranteed. In this research, in order to reduce the controller complexity, a decentralized control method based on robust QFT method is used for STATCOM controller.

\section{Dynamic model of study system:}

Non-linear dynamic model: A non-linear dynamic model of the system is derived by disregarding the resistances of all components of the system (generator, transformer, transmission line and shunt converter transformer) and the transients of the transmission lines and transformer of the STATCOM. The nonlinear dynamic model of the system is given as below ${ }^{[11]}$ :

$$
\left\{\begin{array}{l}
\dot{\omega}=\left(\mathrm{P}_{\mathrm{m}}-\mathrm{P}_{\mathrm{c}}-\mathrm{D} \omega\right) / \mathrm{M} \\
\dot{\delta}=\omega_{0}(\omega-1) \\
\dot{\mathrm{E}}_{\mathrm{q}}^{\prime}=\left(-\mathrm{E}_{\mathrm{q}}+\mathrm{E}_{\mathrm{fd}}\right) / \mathrm{T}_{\mathrm{do}}^{\prime} \\
\dot{\mathrm{E}}_{\mathrm{fd}}=\left(-\mathrm{E}_{\mathrm{fd}}+\mathrm{K}_{\mathrm{a}}\left(\mathrm{V}_{\mathrm{ref}}-\mathrm{V}_{\mathrm{t}}\right)\right) / \mathrm{T}_{\mathrm{a}} \\
\dot{\mathrm{V}_{\mathrm{dc}}}=\frac{3 \mathrm{~m}_{\mathrm{E}}}{4 \mathrm{C}_{\mathrm{dc}}}\left(\sin \left(\delta_{\mathrm{E}}\right) \mathrm{I}_{\mathrm{Ed}}+\cos \left(\delta_{\mathrm{E}}\right) \mathrm{I}_{\mathrm{Eq}}\right)
\end{array}\right.
$$

Linear dynamic model: A linear dynamic model is obtained by linearising the non-linear model around an operating condition. The linearised model is given below:

$$
\left\{\begin{array}{l}
\Delta \dot{\delta}=\omega_{0} \Delta \omega \\
\Delta \dot{\omega}=\left(-\Delta \mathrm{P}_{\mathrm{e}}-\mathrm{D} \Delta \omega\right) / \mathrm{M} \\
\Delta \dot{\mathrm{E}}_{\mathrm{q}}^{\prime}=\left(-\Delta \mathrm{E}_{\mathrm{q}}+\Delta \mathrm{E}_{\mathrm{fd}}\right) / T_{\mathrm{do}}^{\prime} \\
\Delta \dot{\mathrm{E}}_{\mathrm{fd}}=-\left(1 / \mathrm{T}_{\mathrm{A}}\right) \Delta \mathrm{E}_{\mathrm{fd}}-\left(\mathrm{K}_{\mathrm{A}} / \mathrm{T}_{\mathrm{A}}\right) \Delta \mathrm{V}_{\mathrm{t}} \\
\Delta \dot{\mathrm{V}}_{\mathrm{dc}}=\mathrm{K}_{7} \Delta \delta+\mathrm{K}_{8} \Delta \mathrm{E}_{\mathrm{q}}^{\prime}-\mathrm{K}_{9} \Delta \mathrm{v}_{\mathrm{dc}}+\mathrm{K}_{\mathrm{cc}} \Delta \mathrm{m}_{\mathrm{E}}+\mathrm{K}_{\mathrm{c} \dot{\mathrm{ce}}} \Delta \delta_{\mathrm{E}}
\end{array}\right.
$$

Where:

$$
\begin{aligned}
& \Delta \mathrm{P}_{\mathrm{e}}=\mathrm{K}_{1} \Delta \delta+\mathrm{K}_{2} \Delta \mathrm{E}_{\mathrm{q}}^{\prime}+\mathrm{K}_{\mathrm{pd}} \Delta \mathrm{v}_{\mathrm{dc}}+\mathrm{K}_{\mathrm{pe}} \Delta \mathrm{m}_{\mathrm{E}}+\mathrm{K}_{\mathrm{p} \delta \mathrm{E}} \Delta \delta_{\mathrm{E}} \\
& \Delta \mathrm{E}_{\mathrm{q}}=\mathrm{K}_{4} \Delta \delta+\mathrm{K}_{3} \Delta \mathrm{E}_{\mathrm{q}}^{\prime}+\mathrm{K}_{\mathrm{qd}} \Delta \mathrm{v}_{\mathrm{dc}}+\mathrm{K}_{\mathrm{qe}} \Delta \mathrm{m}_{\mathrm{E}}+\mathrm{K}_{\mathrm{q} \delta \mathrm{E}} \Delta \delta_{\mathrm{E}} \\
& \Delta \mathrm{V}_{\mathrm{t}}=\mathrm{K}_{5} \Delta \delta+\mathrm{K}_{6} \Delta \mathrm{E}_{\mathrm{q}}^{\prime}+\mathrm{K}_{\mathrm{vd}} \Delta \mathrm{v}_{\mathrm{dc}}+\mathrm{K}_{\mathrm{ve}} \Delta \mathrm{m}_{\mathrm{E}}+\mathrm{K}_{\mathrm{v} \delta \mathrm{E}} \Delta \delta_{\mathrm{E}}
\end{aligned}
$$

Figure 2 shows the transfer function model of the system including STATCOM. The model has 20 constants denoted by $\mathrm{K}$. These constants are functions of the system parameters and the initial operating condition.

The control vector $U$ in Fig. 2 is defined as follows:

$$
\mathrm{U}=\left[\begin{array}{ll}
\Delta \mathrm{m}_{\mathrm{E}} & \Delta \delta_{\mathrm{E}}
\end{array}\right]^{\mathrm{T}}
$$




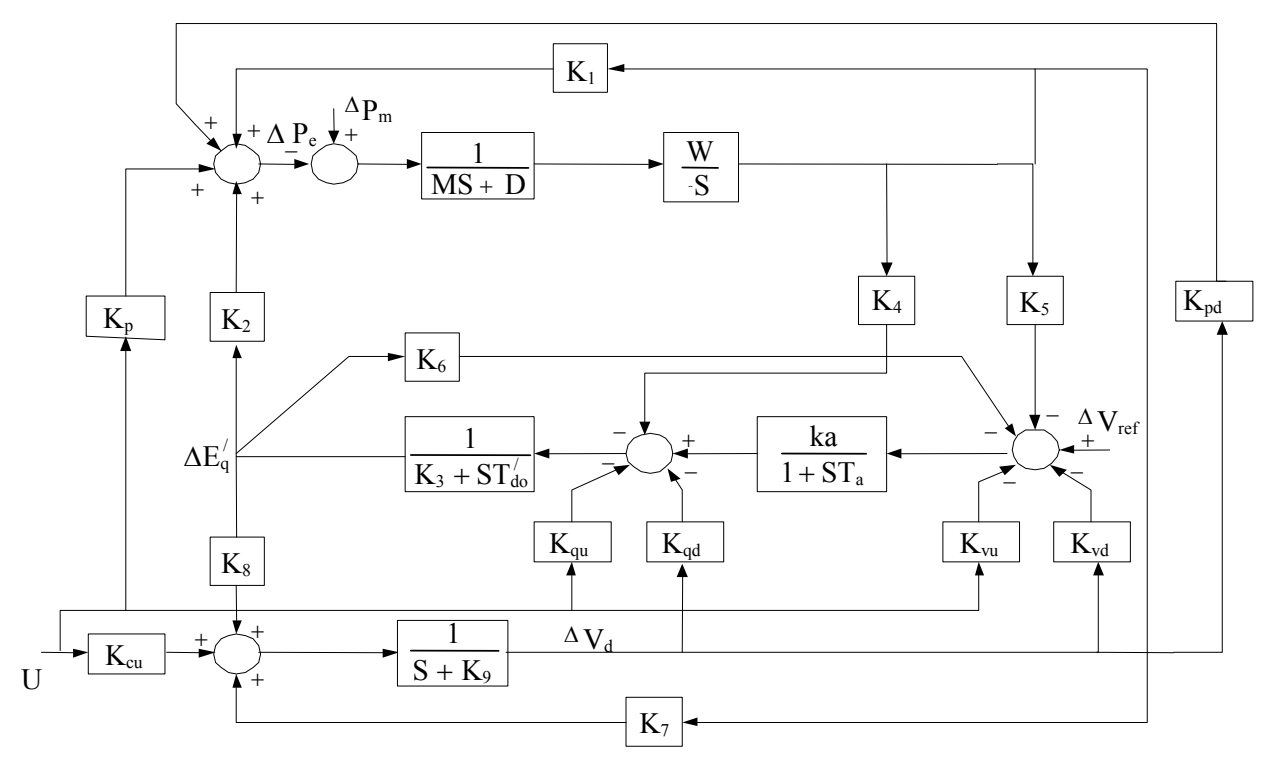

Fig. 2: Linearised dynamic model of the SMIB power system with STATCOM

Where:

$\Delta \mathrm{m}_{\mathrm{E}}=$ Deviation in pulse width modulation index $\mathrm{m}_{\mathrm{E}}$ of shunt inverter. By controlling $\mathrm{m}_{\mathrm{E}}$, the output voltage of the shunt converter is controlled

$\Delta \delta_{\mathrm{E}}=$ Deviation in phase angle of the shunt inverter voltage. By controlling $\delta_{\mathrm{E}}$, exchanging active power between the STATCOM and the power system is controlled

It may be noted that $\mathrm{K}_{\mathrm{pu}}, \mathrm{K}_{\mathrm{qu}}, \mathrm{K}_{\mathrm{vu}}$ and $\mathrm{K}_{\mathrm{cu}}$ in Fig. 2 are the row vectors defined below:

$$
\begin{aligned}
\mathrm{K}_{\mathrm{pu}} & =\left[\begin{array}{ll}
\mathrm{K}_{\mathrm{pe}} & \mathrm{K}_{\mathrm{p} \delta \mathrm{e}}
\end{array}\right] ; \mathrm{K}_{\mathrm{qu}}=\left[\begin{array}{ll}
\mathrm{K}_{\mathrm{qe}} & \mathrm{K}_{\mathrm{q} \delta \mathrm{e}}
\end{array}\right] \\
\mathrm{K}_{\mathrm{vu}} & =\left[\begin{array}{lll}
\mathrm{K}_{\mathrm{ve}} & \mathrm{K}_{\mathrm{v} \delta \mathrm{e}}
\end{array}\right] ; \mathrm{K}_{\mathrm{cu}}=\left[\begin{array}{ll}
\mathrm{K}_{\mathrm{ce}} & \mathrm{K}_{\mathrm{c} \delta \mathrm{e}}
\end{array}\right]
\end{aligned}
$$

Dynamic model in state-space form: The dynamic model of the system in state-space from transferfunction model is as (4):

$$
\left[\begin{array}{c}
\Delta \dot{\delta} \\
\dot{\dot{w}} \\
\dot{\dot{E}_{q}^{\prime}} \\
\Delta \dot{E_{f d}} \\
\dot{\Delta \dot{v}_{d c}}
\end{array}\right]=\left[\begin{array}{ccccc}
0 & w_{0} & 0 & 0 & 0 \\
-\frac{K_{1}}{M} & 0 & -\frac{K_{2}}{M} & 0 & -\frac{K_{p d}}{M} \\
-\frac{K_{4}}{T_{d o}^{\prime}} & 0 & -\frac{K_{3}}{T_{d o}^{\prime}} & \frac{1}{T_{d o}^{\prime}} & -\frac{K_{q d}}{T_{d o}^{\prime}} \\
-\frac{K_{A} K_{5}}{T_{A}} & 0 & -\frac{K_{A} K_{6}}{T_{A}} & -\frac{1}{T_{A}} & -\frac{K_{A} K_{v d}}{T_{A}} \\
K_{7} & 0 & K_{8} & 0 & -K_{9}
\end{array}\right] \times\left[\begin{array}{l}
\Delta \delta \\
\Delta w \\
\Delta E_{q}^{\prime} \\
\Delta E_{f d} \\
\Delta v_{d c}
\end{array}\right]
$$

$$
+\left[\begin{array}{cc}
0 & 0 \\
-\frac{\mathrm{K}_{\mathrm{pe}}}{\mathrm{M}} & -\frac{\mathrm{K}_{\mathrm{pse}}}{\mathrm{M}} \\
-\frac{\mathrm{K}_{\mathrm{qe}}}{\mathrm{T}_{\mathrm{do}}^{\prime}} & -\frac{\mathrm{K}_{\mathrm{qse}}}{\mathrm{T}_{\mathrm{do}}^{\prime}} \\
-\frac{\mathrm{K}_{\mathrm{A}} \mathrm{K}_{\mathrm{ve}}}{\mathrm{T}_{\mathrm{A}}} & -\frac{\mathrm{K}_{\mathrm{A}} \mathrm{K}_{\mathrm{vse}}}{\mathrm{T}_{\mathrm{A}}} \\
\mathrm{Kce} & \mathrm{K}_{\mathrm{c} \delta e}
\end{array}\right] \times\left[\begin{array}{c}
\Delta \mathrm{m}_{\mathrm{E}} \\
\Delta \delta_{\mathrm{E}}
\end{array}\right]
$$

The typical values of system parameters for nominal operating condition are given in Appendix. The system parametric uncertainties are obtained by changing parameters and load (active and reactive power) by $45 \%$ simultaneously from their typical values.

STATCOM controllers: The STATCOM control system comprises three controllers:

- AC-voltage regulator (generator terminals voltage regulator)

- DC-voltage regulator

- Power system oscillations damping controller

AC-voltage and DC-voltage regulators: Figure 3 shows the structure of the AC-voltage regulator. ACvoltage regulator controls the generator terminals voltage and it is regulated by modulating the magnitude of the shunt converter voltage $\left(\mathrm{m}_{\mathrm{E}}\right)$. DC-voltage regulator controls the DC-voltage across the DC 
Am. J. Engg. \& Applied Sci., 1 (1): 66-75, 2008

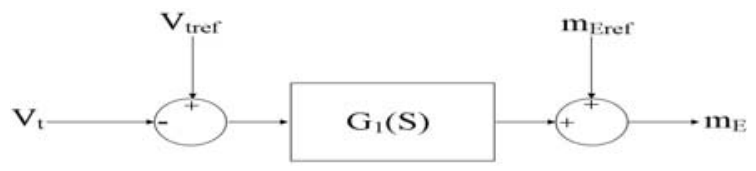

Fig. 3: AC-voltage regulator

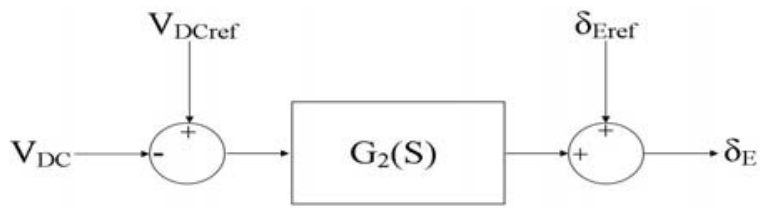

Fig. 4: DC-voltage regulator

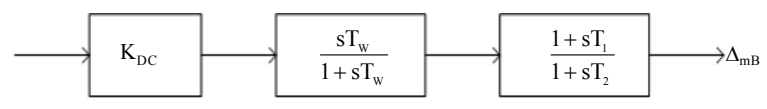

Fig. 5: Structure of damping controller

Table 1: Eigen-values of the closed-loop without damping controller $-18.3561$

$0.0418 \pm 3.4357 \mathrm{i}$

$-0.5689 \pm 0.4670 \mathrm{i}$

capacitor of the STATCOM and it is regulated by modulating the phase angle of the shunt converter voltage $\left(\delta_{\mathrm{E}}\right)$. Figure 4 shows the dynamic model of the DC-voltage regulator. The DC-voltage regulator functions by exchanging active power between the STATCOM and the power system.

Power system oscillation-damping controller: A damping controller is provided to improve the damping of power system oscillations. This controller may be considered as a lead-lag compensator ${ }^{[25-26]}$ or a fuzzy controller block $^{[27]}$. However an electrical torque in phase with the speed deviation is to be produced in order to improve the damping of the system oscillations. The transfer function block diagram of the damping controller is shown in Fig. 5.

Analysis: For nominal operating condition, the eigenvalues of the system (Table 1) are obtained usage statespace from transfer-function model of system in (4) and it is clearly seen that the system is unstable.

Design of damping controller for stability: The damping controllers are designed to produce an electrical torque in phase with the speed deviation according to phase compensation method. The two control parameters of the STATCOM $\left(\mathrm{m}_{\mathrm{E}}\right.$ and $\left.\delta_{\mathrm{E}}\right)$ can be modulated in order to produce the damping torque. In this study $\mathrm{m}_{\mathrm{E}}$ is modulated in order to damping

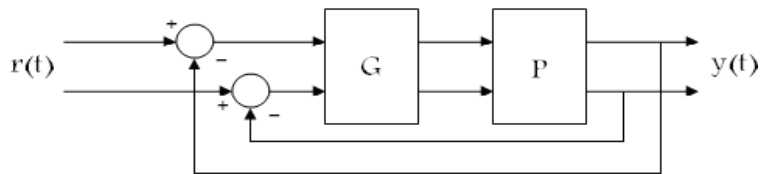

Fig. 6: The MIMO control structure $(2 \times 2)$ system

Table 2: Eigen-value of the closed-loop with damping controller $-18.457,-15.3678,-3.7891$

$-0.8932 \pm 0.5341 \mathrm{i}$

$-0.7301,-0.118$

controller design. The speed deviation $\Delta \omega$ is considered as the input to the damping controller. The structure of damping controller is shown in Fig. 5. It consists of gain, signal washout and phase compensator blocks. The parameters of the damping controller are obtained using the phase compensation technique. The detailed step-by-step procedure for computing the parameters of the damping controllers using phase compensation technique is presented $\mathrm{in}^{[25,26]}$. Damping controller $\mathrm{m}_{\mathrm{E}}$ was designed and obtained as follows (wash-out block is considered). Damping controller of AC-voltage regulator with damping ratio of 0.5 is:

$$
\text { Damping controller }=\frac{412.721 \mathrm{~s}(\mathrm{~s}+4.01)}{(\mathrm{s}+0.1)(\mathrm{s}+5.573)}
$$

After employ this damping controller to system, the eigen-values of the system with damping controller are obtained (Table 2) and it is clearly seen that the system is stable.

Design of statcom controllers: After stability of system using damping controller, The STATCOM ACvoltage and DC-voltage regulators are designed simultaneously based on QFT technique. Because two controllers must be designed simultaneously, therefore, there is a $2 \times 2$ MIMO system and the technique of design for MIMO systems is necessary. According to $\mathrm{QFT}^{[20-22]}$ method and using fixed point theory ${ }^{[23-24]}$ the MIMO problem for a $2 \times 2$ system can be decentralized into 2 equivalent single-loops MISO systems. Each MISO system design is based upon the specifications relating its output and all of its inputs. The basic MIMO compensation structure for a $2 \times 2$ MIMO system is shown in Fig. 6. That consists of the uncertain plant matrix $\mathrm{P}$ and the diagonal compensation matrix $\mathrm{G}$. These matrices are defined as 6 .

$$
\begin{aligned}
& P(s)=\left[P_{i j}\right](s)=\left[\begin{array}{ll}
P_{11} & P_{12} \\
P_{21} & P_{22}
\end{array}\right] \\
& G(s)=\operatorname{diag}\left\{G_{i}(s)\right\}=\left[\begin{array}{cc}
G_{1} & 0 \\
0 & G_{2}
\end{array}\right]
\end{aligned}
$$


Fixed point theory develops a mapping that permits the analysis and synthesis of a MIMO control system by a set of equivalent MISO control system. For $2 \times 2$ system, this mapping results in 2 equivalent systems, each with two inputs and one output. One input is designated as a desired input and the other as a disturbance input. The inverse of the plant matrix is represented by 7 :

$$
\mathrm{P}(\mathrm{s})^{-1}=\left[\begin{array}{ll}
\mathrm{P}^{*}{ }_{11} & \mathrm{P}^{*}{ }_{12} \\
\mathrm{P}^{*}{ }_{21} & \mathrm{P}^{*}{ }_{22}
\end{array}\right]
$$

The 2 effective plant transfer function are formed as 8:

$$
\mathrm{q}_{\mathrm{ij}}=\frac{1}{\mathrm{p}^{*} \mathrm{ij}}=\frac{\operatorname{det} \cdot \mathrm{p}}{\operatorname{adj} \cdot \mathrm{p}_{\mathrm{ij}}}
$$

There is a requirement that det. $\mathrm{P}$ be minimum phase. The Q matrix is then formed as 9:

$$
\mathrm{Q}=\left[\begin{array}{ll}
\mathrm{q}_{11} & \mathrm{q}_{12} \\
\mathrm{q}_{21} & \mathrm{q}_{22}
\end{array}\right]=\left[\begin{array}{cc}
\frac{1}{\mathrm{P}^{*}{ }_{11}} & \frac{1}{\mathrm{P}^{*}{ }_{12}} \\
\frac{1}{\mathrm{P}^{*}{ }_{21}} & \frac{1}{\mathrm{P}^{*}{ }_{22}}
\end{array}\right]
$$
form:

The matrix $P^{-1}$ is partitioned to the following

$$
\mathrm{P}^{-1}=\left[\mathrm{P}^{*}{ }_{\mathrm{ij}}\right]=\left[\frac{1}{\mathrm{q}_{\mathrm{ij}}}\right]=\Lambda+\mathrm{B}
$$

where, $\Lambda$ and $\mathrm{B}$ are the diagonal and balance parts of $\mathrm{p}^{-1}$ According to Fig. 6 the system control ration relating $\mathrm{r}$ to $\mathrm{y}$ is $\mathrm{T}=[\mathrm{P}+\mathrm{PG}]^{-1}$. Pre multiplying of system control ration by $[\mathrm{I}+\mathrm{PG}]$ yields: $[\mathrm{I}+\mathrm{PG}] \mathrm{T}=\mathrm{PGF}$.

When $\mathrm{P}$ is nonsingular, pre multiplying both sides of this equation by $\mathrm{P}^{-1}$ yields:

$\left[\mathrm{P}^{-1}+\mathrm{G}\right] \mathrm{T}=\mathrm{GF}$

Using (10) and with $\mathrm{G}$ diagonal, $\left[\mathrm{P}^{-1}+\mathrm{G}\right] \mathrm{T}=\mathrm{GF}$ can be rearranged as (11):

$$
\mathrm{T}=[\Lambda+\mathrm{G}]^{-1}[\mathrm{GF}-\mathrm{BT}]
$$

This Eq. is used to define the desired fixed point mapping where each of the 4 matrix elements on the right side of this Eq. can be interpreted as a MISO problem. Proof of the fact that design of each MISO system yields a satisfactory MIMO design is based on the Schauder fixed point theorem ${ }^{[23]}$. For each MISO system there is a disturbance input which is a function of all the other loop output. The object of the design is to have each loop track its desired input while minimizing the output due to the disturbance inputs.

Based on this description, in $2 \times 2$ system that we need to design of 2 controllers for STATCOM, the plant matrix $\mathrm{P}$ is a $2 \times 2$ matrix and the diagonal compensation matrix $\mathrm{G}$ contain two compensators of $\mathrm{G}_{1}$ and $\mathrm{G}_{2}$.

Using dynamic state-space model for the SMIB system presented in (4) and defined uncertainties in Appendix, plant matrix P shown in Fig. 7 is obtained as an uncertain plant. According to QFT method and Fig. 7, the structure of control system may be shown as Fig. 8.

Where, $\mathrm{P}$ is the plant transfer function matrix which contain uncertainty parameters and can be obtained using state space form (4) for any operating point, $G_{1}$ and $G_{2}$ are cascading compensators. The object of the design of $G_{1}$ and $G_{2}$ is to have $V_{t}$ and $V_{D C}$ track its desired input while minimizing the output due to the disturbance inputs for all family of plants (system uncertainties). System operating conditions were defined in Appendix, according to this operating conditions and corresponding plant transfer functions, the effective plant transfer functions defined in $(9)\left(\mathrm{q}_{11}\right.$ and $\mathrm{q}_{22}$ ) can be obtained for any operating condition. Then according to fixed point theory, AC-voltage regulator $\left(\mathrm{G}_{1}\right)$ designed based on the effective plant transfer function of $\mathrm{q}_{11}$ and DC-voltage regulator $\left(\mathrm{G}_{2}\right)$ designed based on the effective plant transfer function of $\mathrm{q}_{22}$.

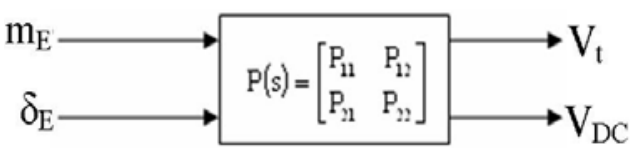

Fig. 7: Open-loop system for AC and DC-voltages control

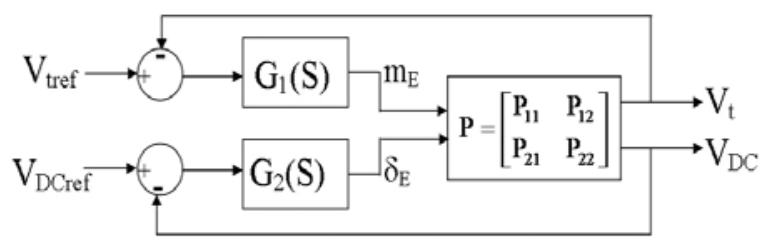

Fig. 8: Closed-loop system for AC and DC-voltage control 


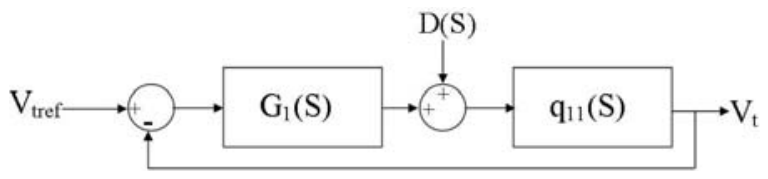

Fig. 9: Structure of closed-loop system for AC-voltage control

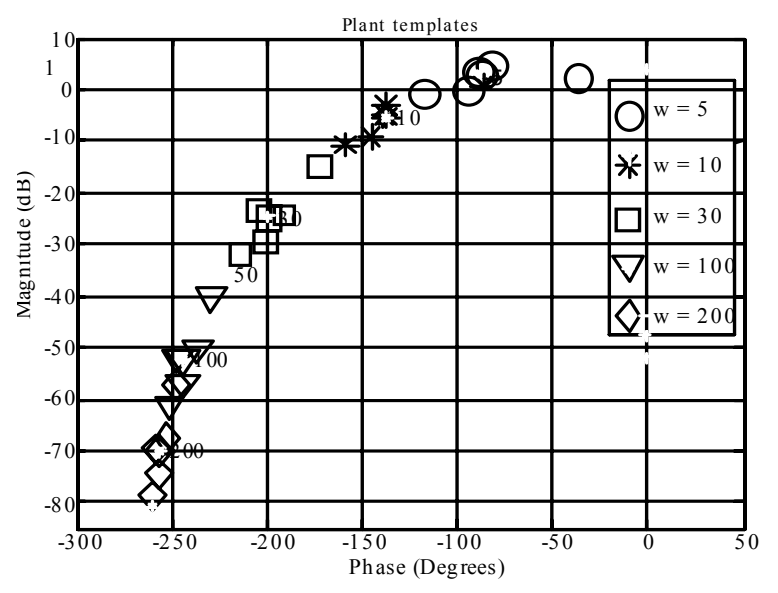

Fig. 10: Templates of effective plant transfer function of $\mathrm{q}_{11}$

Design of AC-voltage regulator: Structure of control system for AC-voltage regulator is shown in Fig. 9. It can be seen clearly that the system is a MISO system and compensator $\mathrm{G}_{1}$ will be designed based on effective transfer function of $\mathrm{q}_{11}$.

Based on QFT technique, the first design step, is plot of plant uncertainty in Nichols diagram. This diagram is known as system templates. Templates of $\mathrm{q}_{11}$ for all operating conditions were obtained by using Matlab $^{\mathrm{TM}}$ software ${ }^{[28]}$ in some frequencies and shown in Fig. 10.

$\mathrm{G}_{1}$ is the cascade compensator and will be designed as which $\mathrm{V}_{\mathrm{t}}$ track its desired input $\left(\mathrm{V}_{\text {tref }}\right)$ while minimizing the output due to the disturbance inputs $(D(S))$, for all uncertainties in the effective plant transfer function of $\mathrm{q}_{11}$.

In this case, because input $\left(\mathrm{V}_{\text {tref }}\right)$ does not change in practice, so just disturbance rejection bounds are considered for design and considering the tracking bounds $\left(B_{R}(j \omega i)\right)$ are not necessary for this design. Output response (generator terminals voltage) is acceptable if the magnitude of the output to be below the limits given by disturbance rejection models. Based on desired performance specification, the disturbance rejections bounds obtained based QFT technique. In this case, because there is not tracking bounds therefore, the disturbance rejections bounds or $\mathrm{B}_{\mathrm{D}}(\mathrm{j} \omega \mathrm{i})$

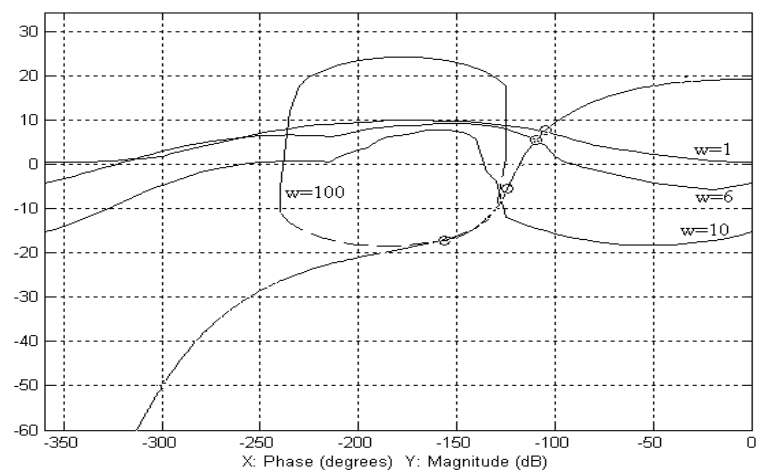

Fig. 11: Bounds and loop shaping for $\mathrm{q}_{11}$

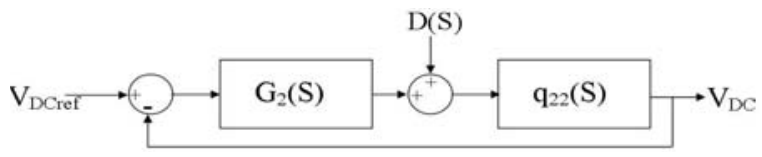

Fig. 12: Structure of closed-loop system for DC-voltage control

are considered as composite bounds $\mathrm{B}_{\mathrm{O}}(\mathrm{j} \omega \mathrm{i})$. Also minimum damping ratios $\zeta$ for the dominant roots of the closed-loop system is considered as $\zeta=1.2$, this amount on the Nichols chart establishes a region which must not be penetrated by the template of loop shaping $\left(\mathrm{L}_{0}\right)$ for all $\omega$. The boundary of this region is referred to as U-contour. The U-contour and composite bound $\mathrm{B}_{\mathrm{O}}\left(\mathrm{j} \omega_{\mathrm{i}}\right)$ and an optimum loop shaping $\mathrm{L}_{01}$ based these bounds, are shown in Fig. 11. And in turn, the compensator $\mathrm{G}_{1}$ obtained as follow:

$$
\mathrm{G}_{1}(\mathrm{~s})=\frac{\mathrm{L}_{01}(\mathrm{~s})}{\mathrm{q}_{11}(\mathrm{~s})} \Rightarrow \mathrm{G}_{1}(\mathrm{~s})=\frac{95.67\left(\mathrm{~S}^{2}+5.998 \mathrm{~S}+10.895\right)}{\mathrm{S}(\mathrm{S}+23.456)\left(\mathrm{S}^{2}+2 \mathrm{~S}+24.654\right)}
$$

Design of DC-voltage regulator: The structure of control system for DC-voltage regulator is shown in Fig. 12. It can be seen clearly that the system is a MISO system and compensator will be designed based on $\mathrm{q}_{22}$.

$\mathrm{G}_{2}$ is a cascade compensator and will be designed as which $\mathrm{V}_{\mathrm{DC}}$ track its desired input $\left(\mathrm{V}_{\mathrm{DCref}}\right)$ while minimizing the output due to the disturbance inputs $(\mathrm{D}(\mathrm{S}))$, for all uncertainties in the effective plant transfer function of $\mathrm{q}_{22}$. Templates of $\mathrm{q}_{22}$ for all operating conditions in some frequencies are shown in Fig. 13.

Because $G_{2}$ is a regulator controller like as $G_{1}$, thus the process for design of $G_{2}$ is as former section and like design of $\mathrm{G}_{1}$. In this case, because input $\left(\mathrm{V}_{\mathrm{DCref}}\right)$ does not change in practice, therefore just disturbance rejection bounds are considered and considering the tracking bounds are not considered for this design. 
Am. J. Engg. \& Applied Sci., 1 (1): 66-75, 2008

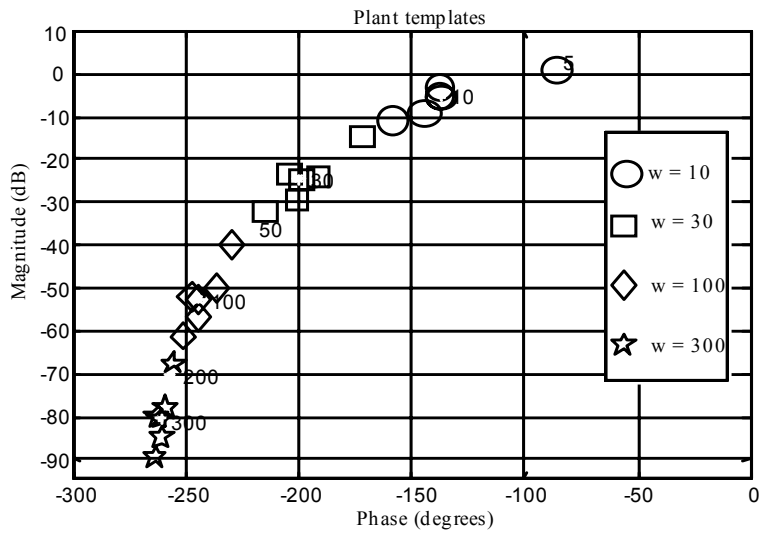

Fig. 13: Templates of effective plant transfer function of $\mathrm{q}_{22}$

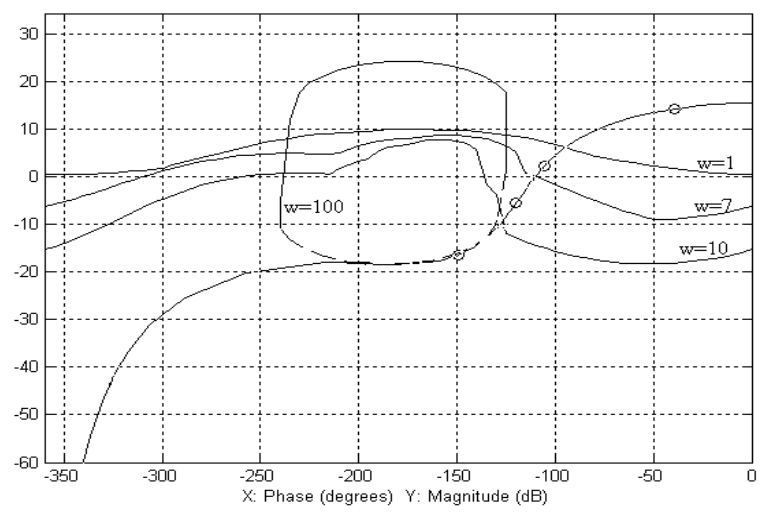

Fig. 14: Bounds and loop shaping for $\mathrm{q}_{22}$

Output response (DC-voltage of shunt converter) is acceptable if the magnitude of the output to be below the limits given by disturbance rejection models. Based on desired performance specification, the disturbance rejections bounds are obtained based QFT technique. Because there is not tracking bounds Therefore, the disturbance rejections bounds $\mathrm{B}_{\mathrm{D}}(\mathrm{j} \omega \mathrm{i})$ are considered as composite bounds $\mathrm{B}_{\mathrm{O}}(\mathrm{j} \omega \mathrm{j})$. The U-contour and composite bound $\mathrm{B}_{\mathrm{O}}(\mathrm{j} \omega \mathrm{i})$ and an optimum loop shaping $\mathrm{L}_{02}$ based these bounds, are shown in Fig. 14. And eventually base QFT technique the compensator $\mathrm{G}_{2}$ obtained as follow:

$$
\mathrm{G}_{2}(\mathrm{~s})=\frac{\mathrm{L}_{02}(\mathrm{~s})}{\mathrm{q}_{22}(\mathrm{~s})}=\frac{1457.0 .85(\mathrm{~S}+1.34)(\mathrm{S}+4.333)(\mathrm{S}+0.133)}{\mathrm{S}(\mathrm{S}+24.05)(\mathrm{S}+2.12)\left(\mathrm{S}^{2}+89.765 \mathrm{~S}+1.234 \mathrm{e} 2\right)}
$$

\section{RESULTS AND DISCUSSION}

In this research different comparative cases are examined to show the effectiveness of proposed QFT

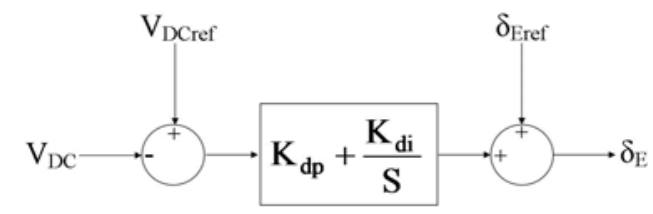

Fig. 15: PI-type DC-voltage regulator

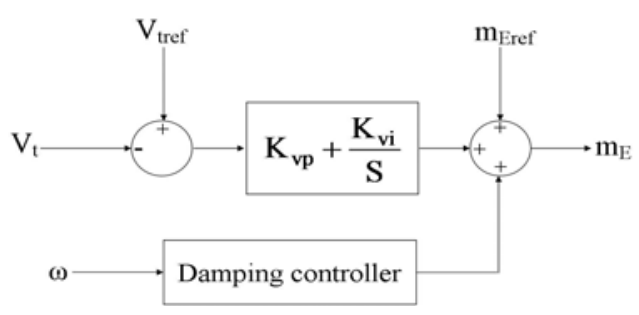

Fig. 16: PI-type AC-voltage regulator with damping controller

controllers. These cases have been evaluated extensively by non-linear and linear time domain simulations, using commercially available software package ${ }^{[28]}$. For comparative studies, each simulation result presented in this research consists of two different plots as optimal controllers and QFT controllers. In the optimal method, P-I type controller is considered for AC-voltage and DC-voltage regulators. Figure 15 and 16 show the transfer function of the P-I type DC-voltage regulator and P-I type AC-voltage regulator, respectively. The parameters of the $\mathrm{AC}$ voltage regulator $\left(\mathrm{K}_{\mathrm{vp}}\right.$ and $\left.\mathrm{K}_{\mathrm{vi}}\right)$ and DC-voltage regulator $\left(\mathrm{K}_{\mathrm{dp}}\right.$ and $\left.\mathrm{K}_{\mathrm{di}}\right)$ are optimized and obtained using $\mathrm{GA}^{[29]}$. Optimum values of the proportional and integral gain setting of the $\mathrm{AC}$-voltage regulator are obtained as $\mathrm{K}_{\mathrm{vp}}=5.56$ and $\mathrm{K}_{\mathrm{vi}}=5.86$. When the parameter of $\mathrm{AC}$-voltage regulator are set at their optimum values, the parameters of DC-voltage regulator are now optimized and obtained as $\mathrm{K}_{\mathrm{dp}}=0.5778$ and $\mathrm{K}_{\mathrm{di}}=0.398$. It should be noted that, the damping controller designed in section $\mathrm{V}$, is considered in the process of optimal controllers design.

In this research time domain simulations based on small disturbance (linear simulations) and large disturbance (non-linear simulations) are shown. The performance of the designed QFT controllers and optimal controllers for STATCOM with same damping controller, after sudden change in mechanical torque (Tm) and short circuit faults were compared and shown in Fig. 17-21.

Linear simulation results: Figure 17-19 show the dynamic responses for a $10 \%$ step change in 
Am. J. Engg. \& Applied Sci., 1 (1): 66-75, 2008
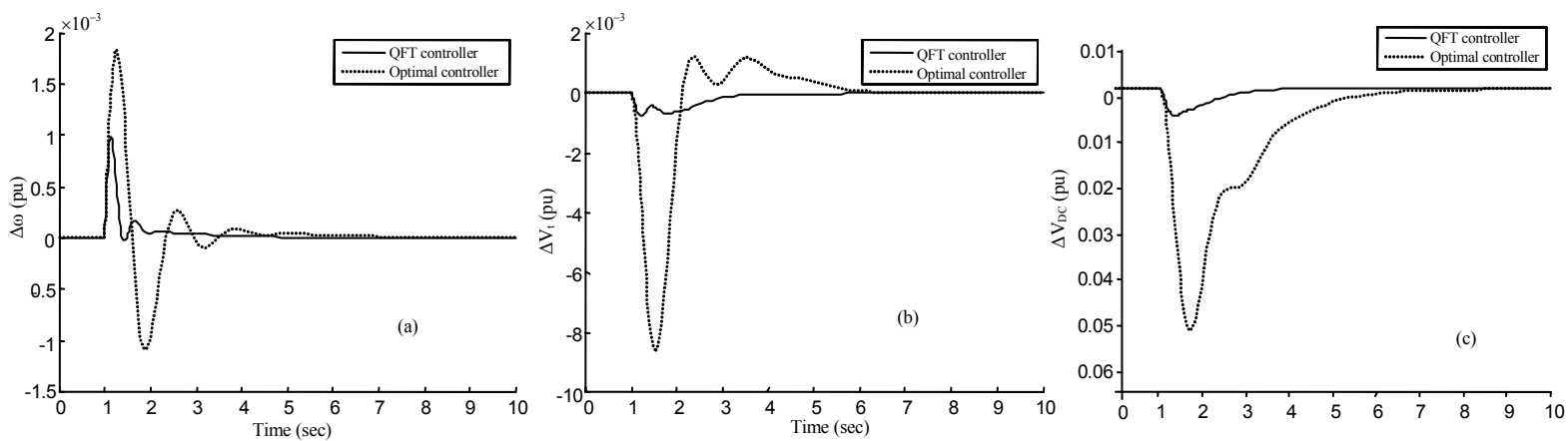

Fig. 17: Dynamic response at nominal load (operating condition 1), following 0.1 step in mechanical torque (Tm), (a): Speed deviation, (b): Terminal voltage deviation and (c): DC-voltage deviation
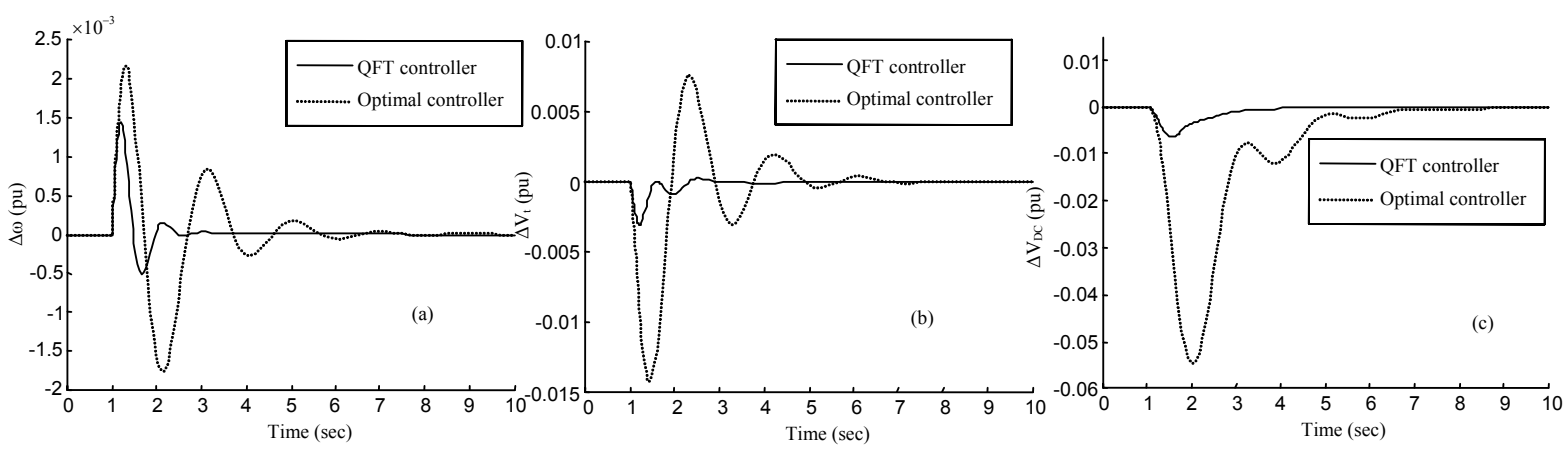

Fig. 18: Dynamic response at very heavy load (operating condition5), following 0.1 step in mechanical torque (Tm), (a): Speed deviation, (b): Terminal voltage deviation and (c): DC-voltage deviation

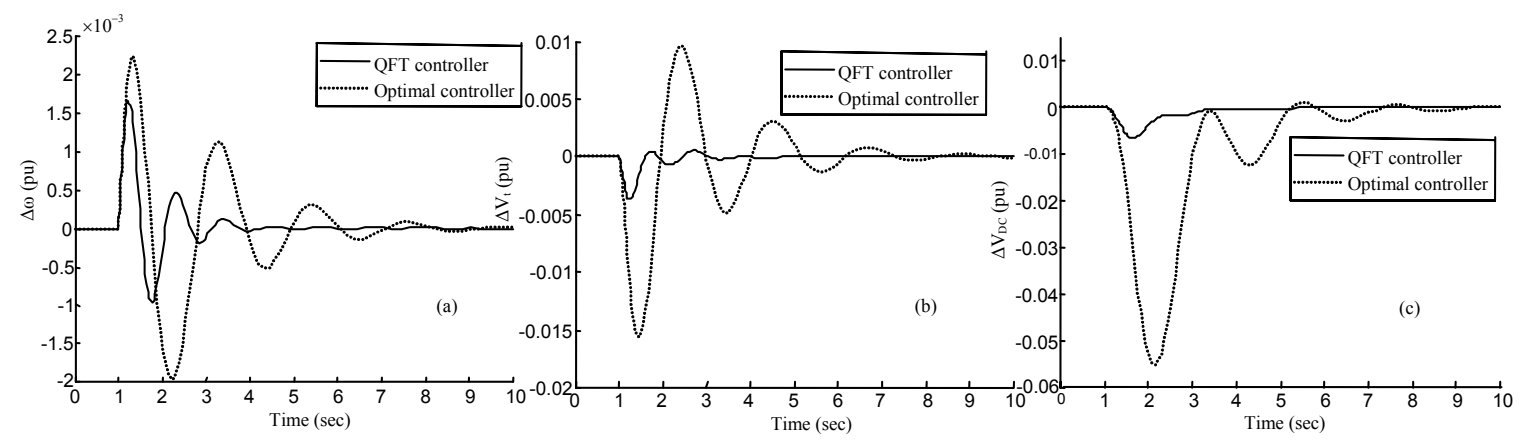

Fig. 19: Dynamic response at very heavy load (operating condition5), following 0.1 step in mechanical torque (Tm), (a): Speed deviation, (b): Terminal voltage deviation, (c): DC-voltage deviation

mechanical torque $(\mathrm{Tm})$, with QFT controllers and optimal controllers, simultaneously.

Figure 17 show the dynamic response at nominal load (operating condition 1), following 0.1 step in mechanical torque $(\mathrm{Tm})$. In this case the proposed method compared with optimal controllers, which have the best stability and performance in power system. To study the performance of controllers against increasing the loads, the dynamic response for heavy load (operating condition 3 ) and very heavy load (operating condition 5) are shown in Figs. 18 and 19. Results show that QFT controllers have a robust performance under a wide range of parameter uncertainty and load conditions, but optimal controllers with increasing the load do not have a good performance and more have the oscillation. 
Am. J. Engg. \& Applied Sci., 1 (1): 66-75, 2008
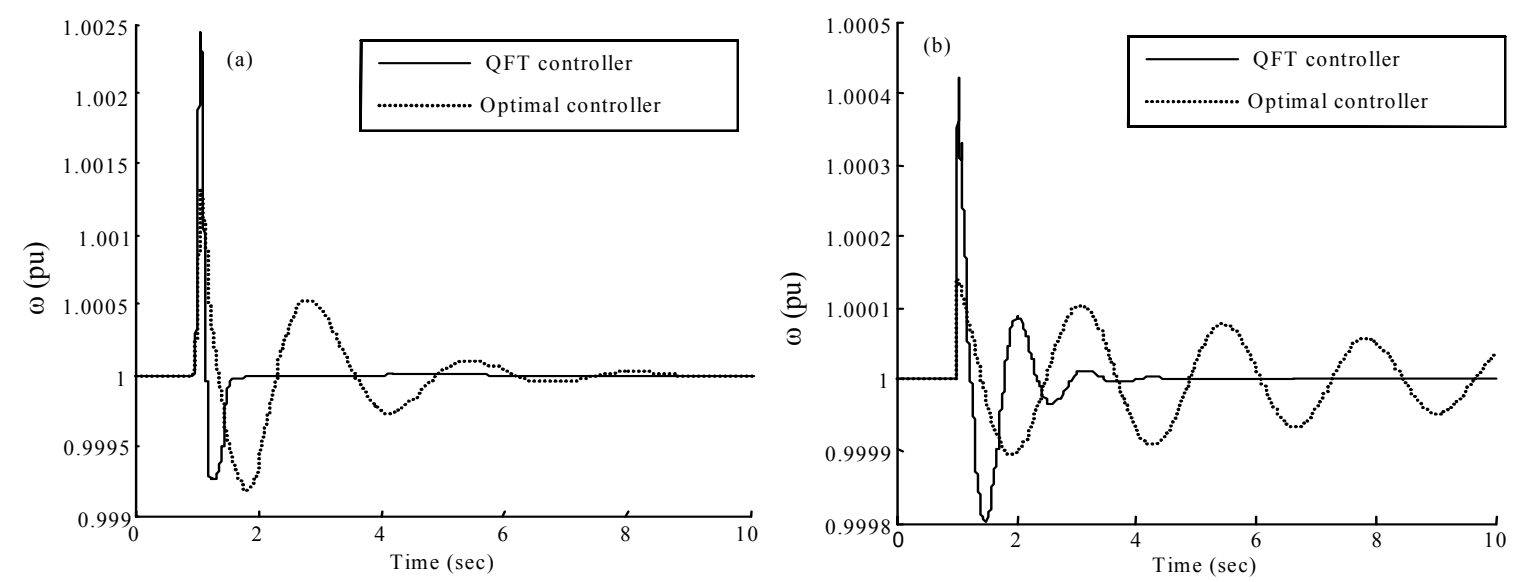

Fig. 20: Dynamic responses for $\omega$ with considering 5 cycle duration transitory 3-phase fault at the infinite bus, (a): Nominal operating condition (operating point 1), (b): Heavy operating condition (operating point 3)
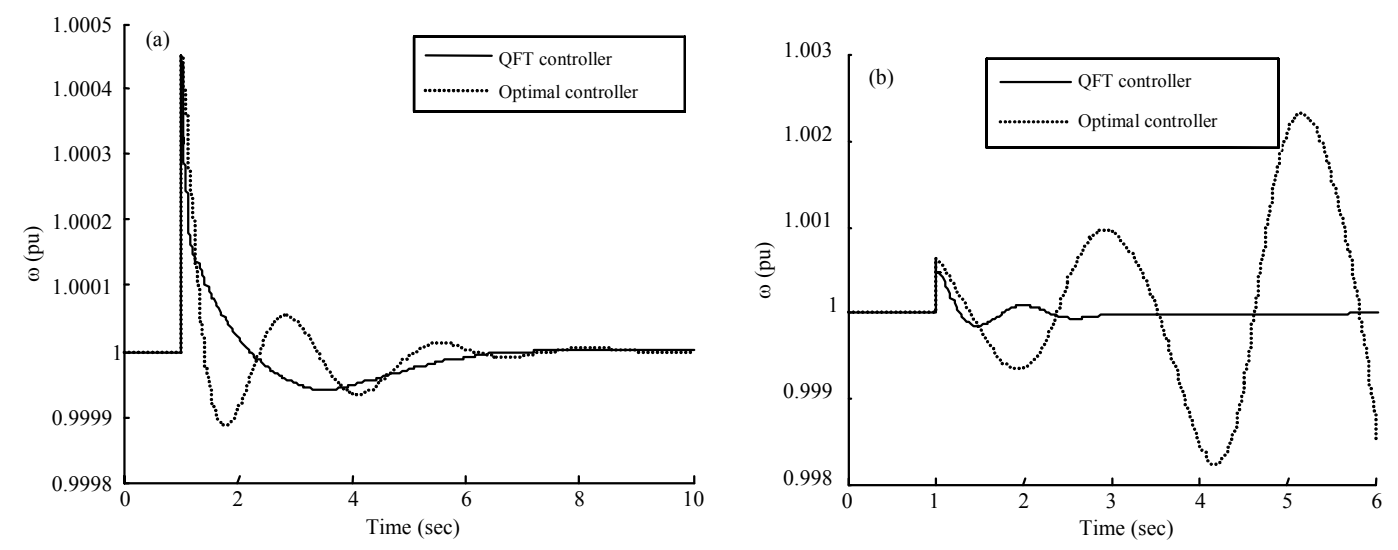

Fig. 21: Dynamic responses for $\omega$ with considering 5 cycle duration transitory 3-phase fault at the generator terminals, (a): Nominal operating condition (operating point 1), (b): Heavy operating condition (operating point 3)

For robustness evaluation of the designed controllers non-linear simulation is required.

Nonlinear simulation results: Non-linear simulations are need for study of large disturbance such as short circuit in power system. To study the effectiveness of proposed QFT controllers for large disturbance, the performance of the designed QFT controllers and optimal controllers after short circuit in infinite bus and generator terminals, were compared and shown in Fig. 20 and 21. Results show that the proposed QFT controllers compared to optimal controllers have the best ability to control of power system under large disturbance and clearly observed that system with optimal controllers going unstable for a 3-phase short circuit. But, QFT controllers are able to stability of system and reduce the power system oscillations.

\section{CONCLUSION}

In this research a robust decentralized STATCOM controllers design based QFT method has been proposed. Design strategy includes enough flexibility to setting the desired level of stability and performance and considering the practical constraint by introducing appropriate uncertainties. The proposed method was applied to a typical SMIB power system installed with an STATCOM including uncertainty parametric and various loads conditions. Simulation results demonstrated that the designed controller capable to guarantee the robust stability and robust performance under a wide range of parameter uncertainty and load conditions. Also, linear and nonlinear simulation results show that the proposed method is robust to change in the parameter of the system and has an excellent 
capability in damping of power system oscillations and enhance of power system stability under small and large disturbances.

\section{REFERENCES}

1. Hingorani, N.G. and Gyugyi L., 2000. Understanding FACTS: Concepts and Technology of FACTS. IEEE Press, John Wiley and sons Inc. New York, $1^{\text {st }}$ edition, ISBN 0-7803-3455.

2. Gyugyi, L., et al., 1990. Advanced static VAR compensator using gate turn-off thyristors for utility applications. CIGRE, 23: 193-203.

3. Gyugyi, L., 1979. Reactive Power generation and control by thyristor circuits. IEEE Trans. Ind. Appl., 15: 521-532.

4. Schauder, C. and A.H. Mehta, 1993. Vector analysis and control of advanced static VAR compensator. IEE Proc., 140: 299-306.

5. Schauder, C., et al., 1995. Development of a \pm 100 MVAR static condenser for voltage control of transmission systems. IEEE Trans. Power Delivery, 10: 1486-1496.

6. Ekanayake, J.B., et al., 1995. Experimental investigation of an advanced static VAR compensator. IEE Proc., 142: 202-210.

7. Saad-Saoud, Z., et al., 1998. Application of STATCOMs to wind farms. IEE Proc., 145: 511-516.

8. Trainner, D.R., et al., 1994. Analysis of GTO-based static VAR compensators. IEE Proc. C, 141: 293-302.

9. Ainsworth, J.D., M. Davies, J.P. Fitz, K.E. Owen and D.R. Trainer, 1998. Static VAR compensator (STATCOM) based on single-phase chain circuit converters. IEE Proc., 145: 381-386.

10. Mori, S., K. Matsuno, K. Takeda and M. Seto, 1993. Development of a large static VAR generator using self-commutated inverters for improving power system stability. IEEE Trans. Power Sys.., IEEE Power Syst., 8: 371-377.

11. Wang, H.F., 1999. Phillips-Heffron model of power systems installed with STATCOM and applications. IEE Proc., 146: 521-527.

12. Heffron, W.G. and R.A. Phillips, 1952. Effect of a modem amplidyne voltage regulator on under excited operation of large turbine generator. AIEE Trans, 71, 692-697.

13. Liou, K.L. and Y.Y. Hsu, 1986. Damping of generator oscillation using static VAR compensator. IEEE Trans. Aerospace Electronic Sys., 22: 605-617.

14. Liou, K.L. and Y.Y. Hsu, 1992. Damping of generator oscillation using an adaptive static VAR comp. IEEE TPWRS, 7: 718-725.
15. Smith, J.R. et al., 1989. An enhanced LQ adaptive VAR unit controller for power system damping. IEEE TPWRS, 4, 443-451.

16. Ni, Y., L. Jiao S. Chen and B. Zhang, 1998. Application of a nonlinear PID controller on STATCOM with a differential tracker. In: International Conference on Energy Management and Power Delivery, EMPD-98, 3-5 March 98, New York, USA, pp: 29-34.

17. Zhao, Q. and J. Jiang, 1995. Robust SVC controller design for improving power system damping. IEEE TPWRS, 10: 1927-1932.

18. Parniani, M. and M.R. Iravani, 1998. Optimal robust control design of static VAR compensators. IEE Proc. C, 145: 301-307.

19. Farsangi, M.M. et al., 2000. Supplementary control design of SVC and STATCOM using $\mathrm{H}_{\infty}$ optimal robust control. In: International Conference Electric Utility Deregulation and Restructuring and Power Technologies, DRPT 2000, 4-7 April 2000, City University London, UK, pp: 355-360.

20. Dazzo, J.J. and C.H. Houpis, 1988. Linear Control System Analysis and Design Conventional and Modern. 3rd Edn. McGraw Hill College, ISBN 0070161860.

21. Horowitz, I., 1982. Quantitative feedback theory. IEE Proc., 129: 215-226.

22. Azvine, B. and R.J. Wynne, 1992. A review of quantitative feedback theory as a robust control system design technique. Trans. Inst. Measur. Control, 14: 265-279.

23. Horowitz, I.M., 1979. Quantitative synthesis of the uncertain multiple input-output feedback systems. Int. J. Control, 30: 81-106.

24. Taher, S.A. and R. Hematti, 2008. Robust decentralized load frequency control using multi variable QFT method in deregulated power systems. Am. J. Applied Sci., 5: 818-828.

25. Wang, H.F., 1999. Damping function of unified power flow controller. IEE Proc., 146: 129-140.

26. Yu, Y.N., 1983. Electric Power System Dynamics. Academic Press Inc., $1^{\text {st }}$ edition, London.

27. Eldamaty, A.A. et al., 2005. Damping PSO using a fuzzy logic based unified power flow controller. IEEE CCECE/CCGEI, 1: 1950-1953.

28. QFT Control Design Toolbox, Mathworks, Inc., 2007.

29. Randy, L.H. and E.H. Sue, 2004. Practical Genetic Algorithms (Book style). 2nd Edn. John Wiley and Sons, Ltd, England, ISBN 0471455652. 